\title{
Classification and Definition of Protein-Calorie Malnutrition
}

\author{
J. C. WATERLOW
}

British Medical fournal, 1972, 3, 566-569

The Eighth Joint Expert Committee on Nutrition of FAO and WHO ${ }^{1}$ emphasized the need for an accepted classification and definition of protein-calorie malnutrition. There are two pressing reasons for this. Bengoa ${ }^{2}$ summarized the available information about the frequency of protein-calorie malnutrition in different countries. There are many gaps, partly because for some countries there are no data, and partly because data which do exist are not always comparable. It is important that studies of prevalence should be extended and that the same criteria should be used everywhere.

Secondly, the prevailing pattern of malnutrition in any region may give some information about the nature of the dietary deficiency and so will have a bearing on the preventive measures which are most appropriate. There are two schools of thought about this. According to what might now be called the classical theory, kwashiorkor results from a deficiency of protein with a relatively adequate energy supply, whereas marasmus is caused by an overall deficiency of energy and protein. From this it follows that where the kwashiorkor syndrome prevails, proteinrich supplements would be an appropriate method of prevention. On the other hand, Gopalan and his co-workers ${ }^{3}$ produced evidence that there are no quantitative or qualitative differences in the diets of children who subsequently develop kwashiorkor or marasmus. They therefore proposed that the difference in the clinical picture reflects not a difference in diet but a difference in the capacity of the child to adapt.

Whichever of these theories is correct the fact remains that according to reports in the literature the prevailing pattern does differ from one country to another. ${ }^{4}$ If the differences are real there must be some reason for them, and the first step in finding the reason is to put the observations on a firm foundation with an agreed system of classification.

The need for this is urgent because an alteration in the pattern of protein-calorie malnutrition and in its age of onset has important implications for the planning of preventive policies.

\footnotetext{
Department of Human Nutrition, London School of Hygiene and Tropical Medicine, London W.C.1

J. C. WATERIOW, M.D., P.R.C.P., Professor
}

\section{General Problems of Classification}

The purpose of a classification is to be useful, and different classifications may be needed in different situations. With protein-calorie malnutrition a qualitative classification is needed to distinguish patterns of severe malnutrition in children admitted to hospital, whereas a quantitative classification is needed in community studies of prevalence and severity.

Secondly, classification of malnutrition must inevitably be arbitrary, and can therefore be determined only by agreement. A classification is of little value unless it is widely accepted, since its main use is to make possible comparisons between results obtained by different people in different places.

Thirdly, to be useful, a classification needs to be simple. An ideal classification of protein-calorie malnutrition would take account simultaneously of three factors-quality, severity, and duration-but this would probably be too complicated to be of practical value.

Community Studies.-When the purpose is to determine the incidence or prevalence of protein-calorie malnutrition in a defined community then what is needed is a classification based on severity so that it is possible to distinguish normal subjects on the one hand and patients with mild, moderate, and severe protein-calorie malnutrition on the other.

\section{Weight for Age}

The well-known classification of Gomez et al. ${ }^{5}$ of first, second, and third degree malnutrition was based on weight for age according to the Boston standards. ${ }^{\circ}$ Cases were not subdivided according to clinical features such as oedema or dermatosis because it was found that these did not affect the prognosis. Bengoa, in his analysis of survey data from many countries, used the Gomez classification but included in third degree malnutrition all cases with oedema regardless of body weight. This is reasonable; no one would deny that the presence of oedema is evidence of rather severe protein-calorie malnutrition. At the same time it reduces the apparent weight deficit.

The major difficulty in classification based on weight for age is that in many communities the ages of children are not known. It may also be considered a disadvantage that an external standard-for example, the Boston standard-is used for comparison. 


\section{Importance of Height}

The Eighth report of the FAO/WHO Expert Committee on Nutrition $^{1}$ emphasized the importance of measurements of height or length, since the extent of height deficit in relation to age may be regarded as a measure of the duration of malnutrition. This concept has been discussed in more detail by Seoane and Latham $^{7}$ and by Waterlow and Alleyne. ${ }^{8}$

The expression of weight in relation to height gives a measure of nutritional status which is independent of age and of agerelated external standards. These are great advantages. As Seoane and Latham pointed out, weight for height is an index of current nutritional status; height for age gives a picture of the past nutritional history. Since these parameters measure different things it is desirable that changes in them should be distinguished by different words. It would be reasonable to confine the use of the words undernutrition and malnutrition to changes in weight in relation to height. This would fit in with the terminology of adult medicine; undernourished and obese mean underweight or overweight for height. A reduction in the rate of linear growth could appropriately be referred to as retardation and a reduction in final stature as stunting.

Children may therefore fall into four broad categories which are qualitatively different: $(a)$ normal; $(b)$ malnourished but not retarded-that is, acute malnutrition; $(c)$ malnourished and retarded-that is, acute on chronic malnutrition; and (d) retarded but not malnourished-the so-called nutritional dwarfs ${ }^{\circ}$ come into this category, and also many children who have recovered from malnutrition. The problem that remains is to put these categories on a quantitative basis and to determine appropriate groupings so that each category is subdivided according to severity.

Deficit in weight for height can easily be calculated from a graph, such as that shown here (see Graph). This is based on the Boston standards for weight and height; nevertheless, it is not an "external" standard of the same kind as absolute weight for age or height for age, because weight for height is a measure of body proportions and should be relatively independent of genetic differences in absolute body size.

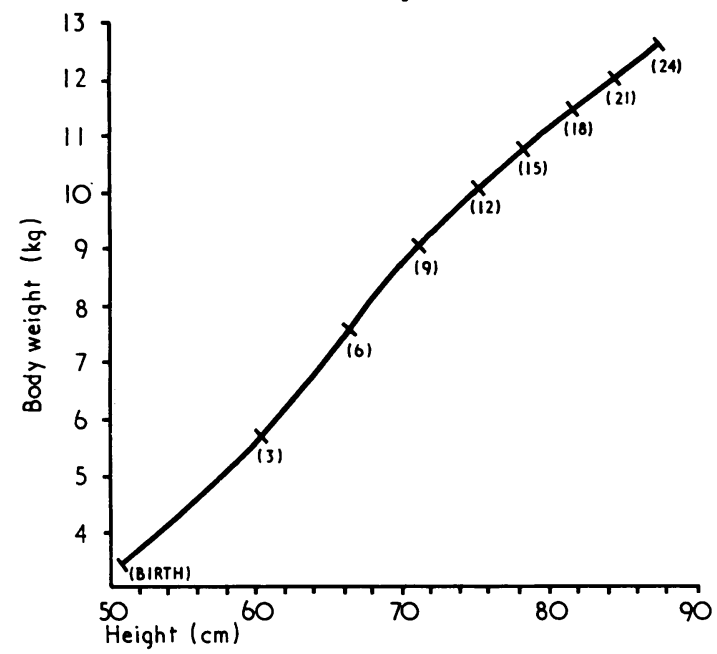

Relation of weight to height during first 2 years of life. Age in months is shown in parentheses. Data from Boston standards, 50 th percentile.

If in addition to normal we recognize three degrees of malnutrition, as shown by deficit in weight for height, and three degrees of retardation, as shown by deficit in height for age, then the resulting classification must have 16 cells. An example is shown in Table I, with a rather arbitrary choice of groupings. Only experience will show whether such a system is too complicated to be useful and whether the groupings are suitable. To simplify it by compounding the two measurements in a single score would defeat the object, which is to distinguish two different processes. Such a classification has an advantage over that of Gomez, in that useful information can be obtained about
TABLE I-Example of $4 \times 4$ Classification according to Degrees of Malnutrition and Retardation. Percentages are Proportion of Children Examined

\begin{tabular}{|c|c|c|c|c|c|c|}
\hline \multicolumn{7}{|c|}{ Retardation } \\
\hline & & Grade: & 0 & 1 & 2 & 3 \\
\hline \multirow[b]{2}{*}{ 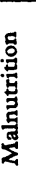 } & \multicolumn{2}{|c|}{$\%$ Expected height for age: } & $>95$ & $95-87 \cdot 5$ & $87 \cdot 5-80$ & $<80$ \\
\hline & $\begin{array}{c}\text { Grade } \\
0 \\
1 \\
2 \\
3\end{array}$ & $\begin{array}{c}\text { \% Expected } \\
\text { Weight for Height } \\
>90 \\
90-80 \\
80-70 \\
<70\end{array}$ & $\begin{array}{l}52 \% \\
2 \% \\
1 \% \\
0\end{array}$ & $\begin{array}{l}31.5 \% \\
7 \% \\
2 \% \\
0\end{array}$ & $\begin{array}{c}3 \% \\
0.5 \% \\
0 \\
0\end{array}$ & $\begin{array}{l}1 \% \\
0 \\
0 \\
0\end{array}$ \\
\hline
\end{tabular}

Expected values $=$ Boston 50 th percentile; $95 \%$ expected height for age $=$ approximately Boston 3rd percentile.

Data from survey of children in Montserrat (W. P. T. James and B. Aksu, unpublished.) Values for male children aged 1-3 years.

one criterion, weight for height, even if ages are not known. It is to be noted that the index "weight as \% of expected (or standard) weight for height" is independent of age.

It is also important not to confuse the "weight as \% of expected weight for height" with the numerical ratio: weight $(\mathrm{kg}) /$ height $(\mathrm{cm})$. Dugdale ${ }^{10}$ and Rao and Singh ${ }^{11}$ pointed out that this latter ratio does vary with age. The 50 th percentile Boston figures show that it increases from $6.7 \times 10^{-2}$ at birth to $14.3 \times 10^{-2}$ at 2 years and $16.9 \times 10^{-2}$ at 5 years. However, if weight is divided by height ${ }^{1 \cdot 6}$ (Dugdale) or by height ${ }^{2}$ (Rao and Singh) the resulting ratio is independent of age. One may question the value of these mathematical manipulations. In fact, it happens that the Dugdale index gives values which are numerically almost exactly the same as the \% weight for height. For example, a child who is $90 \%$ of weight for height will have a Dugdale index of 88 , and the relation between the two indices seems to be linear over the range in which we are likely to be interested.

\section{Other anthropometric measurements}

Many different anthropometric measurements are now used to a varying extent in nutritional surveys. It is not the purpose here to discuss their significance, except in so far as they may contribute to a method of classification.

Jelliffe and Jelliffe ${ }^{12}$ recently discussed so-called age-independent measurements. They concluded that such measurements are not strictly independent of age; they "do not need a knowledge of exact age to the month or week, but do require approximate age categorisation." From the point of view of classification it is evident that there can be no age-independent estimate of retardation, because by definition retardation refers to the relation between a given value and age. Secondly, no single measurement can give an age-independent estimate of malnutrition, in the sense in which the term is defined above, because all bodily measurements alter with age. However, probably more or less valid age-independent estimates can be obtained by ratios of two measurements other than age. Weight for height is the most obvious example.

An index which may be of practical use, particularly in emergency situations, is the ratio of arm circumference to height. Essentially this gives the same information as weight for height, since a thin person tends to have a thin arm, but it is less sensitive and accurate. This is partly because the arm circumference is a linear measurement whereas weight is a cubic one, and partly because the percentage error in measurement is likely to be greater. On the other hand, arm circumference combined with skin-fold thickness gives information which is not obtainable in any other way, since it distinguishes between a thin muscular child and an apparently well-nourished but flabby one.

\section{Composite Classification}

An example of a composite classification is that of Burgess et al. ${ }^{13}$ Children were classified as having protein-calorie malnutrition 
if they had three or more signs, of which one had to be anthropometric. The clinical signs were hair changes, depigmented face, moon-face, hepatomegaly without splenomegaly, and oedema. The positive anthropometric signs were chest:head ratio of less than 1, mid-upper arm muscle circumference less than $80 \%$ of standard, and weight for length less than $80 \%$ of standard. This classification seems unacceptable for several reasons. Equal weight is given to clinical signs which have very different real importance-for example, depigmentation of the face and oedema. The three anthropometric signs probably all provide much the same information, and, therefore, to give them each separate weighting confuses the picture. In this particular classification no grading was attempted into different degrees of severity.

\section{Classification of Severe Forms}

Here the problem is to determine the relative frequency of different patterns of severe protein-calorie malnutrition, as they present, for example, at a hospital or clinic. Attention is concentrated on qualitative differences, but severity is also important in relation to prognosis, rate of recovery, the extent of permanent after effects, etc. Although a qualitative classification is not concerned with incidence or prevalence it is essential that the population being studied should be defined and the criteria clearly stated by which the children are admitted to the study and labelled as protein-calorie malnutrition, otherwise comparisons between different places may be biased from the start.

All workers agree that within the population of severe protein-calorie malnutrition the different clinical and biochemical features present a continuous spectrum. In the past different workers have attached special significance to one or other of the clinical features making up the syndrome to which Cicely Williams gave the name kwashiorkor. Trowell ${ }^{14}$ put stress on dermatosis, Waterlow ${ }^{15}$ on hepatomegaly and fatty liver, and Brock and Autret ${ }^{16}$ on red hair. None of these became accepted as the main diagnostic criterion because to some extent they seem to reflect regional differences in pattern. On the other hand, virtually all workers agree that oedema must be present before the diagnosis of kwashiorkor is made. All subsequent qualitative classifications are based on this, with varying emphasis on the other features.

For example, Garrow ${ }^{17}$ analysed a series of cases of severe malnutrition in Jamaica according to the following criteria. (a) No child was considered to be severely malnourished unless he was below $70 \%$ of the expected weight for age (Boston standards). (b) The criteria for kwashiorkor were: child at minimum weight not less than $60 \%$ of expected weight for age; oedema present, plus either hepatomegaly or dermatosis. (c) The criteria for marasmus were that the child should be less than $60 \%$ of expected weight for age and have no oedema or other specific signs. (d) Children who were less than $60 \%$ of expected weight, with oedema or other signs, were classified as intermediate (marasmic kwashiorkor). These formed the largest group-nearly $70 \%$ of all cases.

McLaren and co-workers ${ }^{18}$ proposed a scoring system for protein-calorie malnutrition in which points were given for oedema, dermatosis, hair changes, hepatomegaly, and serum albumin or total protein levels. No criterion was laid down for admitting a child into the classification. A realistic feature of the system is that it gives more weight to oedema than to the other clinical signs. However, since oedema is almost always associated with some degree of hypoalbuminaemia, one sign is in effect given double weight; it is a matter of opinion whether or not this is desirable. It is also a disadvantage for international comparisons that the score should depend on a laboratory measurement which may not always be possible and the results of which may not be comparable when obtained in different places by different methods.

A simple classification was proposed by the Wellcome working party which met in 1969.10 The point at which malnutrition begins was defined as a reduction in body weight below $80 \%$ of the Boston 50th percentile. This corresponds approximately to the Boston 3rd percentile. The malnourished children are classified according to only two criteria: the presence or absence of oedema and a body weight above or below $60 \%$ of the Boston standard weight for age (50th percentile). This gives rise to four cells, as shown in Table II. No weight was given to other features, such as hepatomegaly or changes in skin and hair, TABLE II-Classification of Protein-Calorie Malnutrition suggested by Well-
come $^{10}$ Working Party*

\begin{tabular}{|c|c|c|c|c|c|}
\hline \multirow{2}{*}{\multicolumn{4}{|c|}{$\begin{array}{l}\text { Weight } \\
\text { (\% of Standard) }\end{array}$}} & \multicolumn{2}{|c|}{ Oedema } \\
\hline & & & & \multirow{2}{*}{ 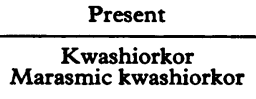 } & \multirow{2}{*}{$\frac{\text { Absent }}{\substack{\text { Undernourished } \\
\text { Marasmus }}}$} \\
\hline $\begin{array}{l}80-60 \\
<60 \ldots\end{array}$ & .. & 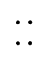 & $\therefore$ & & \\
\hline
\end{tabular}

*Standard $=50$ th percentile Boston values.

because these were felt to be associated rather than essential features of the syndrome. Obviously any clinician using this classification should also record the frequency of such changes in each group.

It is a disadvantage of the Wellcome classification that it takes no account of retardation and hence of the duration of malnutrition. To introduce this as a separate element into the classification would make it rather complicated, but weight for height might be substituted for weight for age when ages are not known. We found that malnourished children who had been grouped according to the Wellcome classification differed in weight for height in much the same way as they differed in weight for age (Table III). More striking is the fact that the children classified as cases of kwashiorkor were significantly less retarded

TABLE III-Heights and Weights of Severely Malnourished Children (famaica) grouped according to Wellcome Classification ${ }^{10}$ (Mean \pm S.D.)

\begin{tabular}{|c|c|c|c|}
\hline & $\begin{array}{c}\text { Kwashiorkor } \\
\qquad(\mathrm{n}=19)\end{array}$ & $\begin{array}{c}\text { Marasmic } \\
\text { Kwashiorkor } \\
(\mathbf{n}=21)\end{array}$ & $\begin{array}{c}\text { Marasmus } \\
(n=20)\end{array}$ \\
\hline $\begin{array}{l}\% \text { Expected weight for age } \ldots \\
\% \text { Expected height for age } \\
\% \text { Expected weight for height }\end{array}$ & $\begin{array}{l}67 \cdot 0 \pm 7 \cdot 5 \\
91 \cdot 8 \pm 3 \cdot 6 \\
80 \cdot 3 \pm 11 \cdot 0\end{array}$ & $\begin{array}{l}47 \cdot 0 \pm 6 \cdot 3 \\
84 \cdot 6 \pm 4 \cdot 5 \\
69 \cdot 5 \pm 8.6\end{array}$ & $\begin{array}{l}45 \cdot 3 \pm 7 \cdot 8 \\
86 \cdot 1 \pm 4 \cdot 8 \\
65 \cdot 7 \pm 8 \cdot 9\end{array}$ \\
\hline
\end{tabular}

in height than those in the other two groups, suggesting that the malnutrition must be of more recent onset. Similar findings were recorded by Graham et al. ${ }^{20}$ in Peru and by Shakir et al..$^{21}$ in Baghdad.

Some may feel that the Wellcome classification is too simple, but its simplicity need not inhibit the recording of additional information. At least, if widely used this system would provide a starting point for comparisons in space and time of differences in the pattern of protein-calorie malnutrition. This is a first step in determining whether or not the syndromes really result from different dietary causes.

\section{Conclusion}

It is extremely important for studies of prevalence and the planning of preventive measures that agreement should be reached about the classification of protein-calorie malnutrition. Probably two classifications will be needed for different situations: (a) for community studies a grading of severity (quantitative classification) into mild, moderate, and severe categories; (b) for severe cases a qualitative classification to distinguish marasmus, kwashiorkor, and intermediate forms.

It is suggested that for community studies classification should be based on two indices. (1) Weight as percentage of expected weight at the given height calculated from the 50th percentile of the Boston standard. This gives a measure of current malnutrition in the strict sense of alteration in body proportions and composition. The index is also age-independent. Limits are proposed for the categories mild, moderate, and severe. (2) I 
age is available, height as percentage of expected height for age, again based on the Boston standard. This is a measure of retardation and therefore of past malnutrition.

For the qualitative classification of severe cases the Wellcome system is proposed. In each group additional data should be recorded so far as possible. It is essential that the criteria for including children in the classification should be clearly laid down.

International comparisons obtained by these methods would be extremely valuable.

\section{References}

1 Joint FAO/WHO Expert Committee on Nutrition, World Health Organization Technical Report Series, No. 477. Geneva, W.H.O., 1971.

2 Bengoa, J. M., WHO Chronicle, 1970, 24, 552.

3 Gopalan, C., in Calorie Deficiencies and Protein Deficiencies, ed. R. A. McCance and E. M. Widdowson. London, Churchill, 1968.

WHO Chronicle, 1972, 26, 160.

5 Gomez, F., et al., Fournal of Tropical Pediatrics, 1956, 2, 77.
- Stuart, H. C., and Stevenson, S. S., in Textbook of Pediatrics, ed. W. E. Nelson, 7th edn., p. 12. Philadelphia, Saunders, 1959.

7 Seoane, N., and Latham, M. C., Fournal of Tropical Pediatrics and Environmental Child Health, 1971, 17, 98.

8 Waterlow, J. C., and Alleyne, G. A. O., Advances in Protein Chemistry, 1971, 25, 117 .,

Monckeberg, F., in Calorie Deficiencies and Protein Deficiencies, ed. R. A. McCance and E. M. Widdowson, p. 91 . London, Churchill, 1968.
ed. R. A. McCance and E. M. Widdowson, p. 91 . London, Churchill, 1968.
Dugdale, A. E., American fournal of Clinical Nutrition, 1971, 24, 174.

11 Rugdale, A. E., American fournal of Clinical Nutrition, 1971, 24, 174.

Rao, V. K., and Singh, D., American fournal of Clinical Nutrition, 1970
J3, 83.
Jelliffe, D. B., and Jelliffe, E. F. P., American fournal of Clinical Nutrition, $1971,24,1377$.

18 Burgess, H. J. L., Maletnlema, N. T., and Burgess, A. P., Tropical and Geographical Medicine, 1969, 21, 39.

14 Trowell, H. C., Transactions of the Royal Society of Tropical Medicine and Hygiene, 1941, 35, 13.

15 Waterlow, J. C., Medical Research Council. Special Report Series, No. 263. 16 Brock, J. F., and Autret, M., World Health Organization. Monograph Series, No. 8, 1952.

17 Garrow, J. S., Archivos Latinamericanos de Nutricion, 1966, 16, 145.

18 Marrow, J. S., Archivos Latinamericanos de Nutricion, 1966, 16, 145.

18 McLaren, D. S., Pellett, P. L., and Read, W. W. C., Lancet, 1967, 1, 533.

19 Lancet, 1970, 2, 302.

Graham, G. C., Cordano, A., and Baertl, M., fournal of Nutrition, 1964, 84, 71.

21 Shakir, A., Demarchi, M., and El-Milli, N., Lancet, 1972, 2, 143.

\title{
Accident Flying Squad
}

\author{
ROGER SNOOK
}

British Medical fournal, 1972, 3, 569-574

\section{Summary}

This paper describes the organization, evaluation, and costing of an independently financed and operated accident flying squad. 132 accidents involving 302 casualties were attended, six deaths were prevented, medical treatment contributed to the survival of a further four, and the condition or comfort of many other casualties was improved. The calls in which survival was influenced were evenly distributed throughout the three-and-a-halfyear survey and seven of the 10 so aided were over 16 and under 30 years of age, all 10 being in the working age group.

The time taken to provide the service was not excessive and the expense when compared with the overall saving was very small. The scheme was seen to be equally suitable for basing on hospital or general practice or both, and working as an integrated team with the ambulance service. The use of specialized transport was found to be unnecessary. Other benefits of the scheme included use of the experience of attending accidents to ensure relevant and realistic training for emergency service personnel, and an appreciation of the effect of ambulance design on the patient.

\section{Introduction}

The concept of this research project developed during the early stages of working in an accident department in 1965, and further impetus came from the experience of chance arrival at the scene of road accidents. In the accident department contact with members of the emergency services was frequent, and I became increasingly aware of the problems that they had to face-in particular, cases for which the resuscitative measures required before admission to hospital were beyond both their training and equipment. This gap between the ambulance and

\section{Royal United Hospital, Bath}

ROGER SNOOK, M.D., Senior Casualty Officer, and Accident Medical Officer to Bath Fire Brigade and Ambulance Service accident services was widened by the fact that hospital equipment was often incompatible with that of the ambulance service.

The project developed in four related stages-lecturing to the ambulance staff, the organization of an independently financed and operated accident flying squad, the introduction of hospital training for the ambulancemen, and the investigation of ambulance design.

In 1966 there was little literature on the organization of medical attendance at accidents in Britain. Hall ${ }^{1}$ and Collins ${ }^{2}$ had described hospital-based teams with medical or nursing staff transported respectively by ambulance and police car, and Easton's scheme involving general practitioners was not started until December 1967..$^{3}$ The major publication was an English translation ${ }^{4}$ describing Professor Gögler's organization in Heidelberg, West Germany. In this scheme medical treatment at accidents was based on the introduction of a large mobile operating theatre unit in 1957.

These three hospital-based schemes all involved the use of specialized transport. The alternative, therefore, was to investigate the usefulness of one doctor attending accidents in his own car and carrying his own equipment. This paper describes the organization, equipment, and evaluation of medical attendance by $m e$ at the scene of accidents and the integration of this within the ambulance service during the three-and-a-half-year period starting in November 1967 after a period of feasibility study. On completion of the research Bath City Council then officially took over the scheme by making it a part of the City Fire and Ambulance Service, including the creation of the appointment of accident medical officer.

\section{Outline of Scheme}

\section{ORGANIZATION}

Initially my attendance at road accidents was more in the role of an observer, to study how the emergency services organized themselves, how best to organize medical participation, and to build up gradually a relationship with the emergency service personnel. In fact, this approach set the pattern for the relationship that was to continue. From the outset medical aid was organized to be available to the emergency services on request and to combine as part of their team at the scene of the incident- 